\title{
MiCHEL COLLOT, Gérard de Nerval, du réel à l'imaginaire
}

\section{Martin Mees}

\section{OpenEdition \\ Journals}

\section{Édition électronique}

URL : https://journals.openedition.org/studifrancesi/45309

DOI : 10.4000/studifrancesi.45309

ISSN : 2421-5856

\section{Éditeur}

Rosenberg \& Sellier

\section{Édition imprimée}

Date de publication : 1 août 2021

Pagination : 392

ISSN : 0039-2944

\section{Référence électronique}

Martin Mees, « міснец Collot, Gérard de Nerval, du réel à l'imaginaire», Studi Francesi [En ligne], 194 (LXV |

II) | 2021, mis en ligne le 01 septembre 2021, consulté le 15 octobre 2022. URL : http://

journals.openedition.org/studifrancesi/45309; DOI : https://doi.org/10.4000/studifrancesi.45309

Ce document a été généré automatiquement le 15 octobre 2022.

\section{(c) (†)}

Creative Commons - Attribution - Pas d'Utilisation Commerciale - Pas de Modification 4.0 International - CC BY-NC-ND 4.0

https://creativecommons.org/licenses/by-nc-nd/4.0/ 


\title{
MICHEL Collot, Gérard de Nerval, du réel à l'imaginaire
}

\author{
Martin Mees
}

\section{RÉFÉRENCE}

Michel Collot, Gérard de Nerval, du réel à l'imaginaire, Paris, Hermann, 2019, 220 pp.

1 L'essai Gérard de Nerval, du réel à l'imaginaire publié récemment par Michel Collot propose aux lectrices et lecteurs la réédition d'un essai de 1992 (Gérard de Nerval ou la dévotion à l'imaginaire, Paris, PUF) qui se trouve augmenté pour l'occasion d'une volumineuse première partie composée à partir de textes inédits et d'articles déjà publiés. Le tout forme un objet composite qui n'aurait pas déplu à Nerval lui-même, grand adepte des reprises et recompositions, mais qui ne manque pas de nous interroger quant aux motifs de sa (re)parution. Car l'ambition de ce nouvel ouvrage ne se limite pas à l'envie de rendre à nouveau accessible un essai qui fit date au sein des études nervaliennes, ni de proposer une synthèse des réflexions de $\mathrm{M}$. Collot sur cet auteur. Sa publication s'inscrit dans le cadre de débats théoriques qui traversent la réception critique de Nerval, et au sein desquels le livre entend se positionner pour défendre et expliciter à nouveaux frais une interprétation qui était déjà celle de la première édition mais qui ne fait pas consensus chez les spécialistes.

2 L'introduction générale comme la quatrième de couverture situent d'emblée l'ouvrage dans une volonté de rééquilibrage de la compréhension que nous avons de l'œuvre nervalienne, trop influencée selon l'auteur par la place qu'ont prise dans la recherche les lectures historiques et contextualisantes. Aux tendances trop positivistes de ces dernières, M. Collot entend opposer une «démarche résolument herméneutique» (p. 9), qui non seulement fait la part belle aux interprétations thématique et stylistique du texte mais emprunte aussi de nombreux concepts à la psychanalyse, pour faire droit in fine à la part irréductible d'«imaginaire» qui innerve l'écriture nervalienne. M. Collot reconnaît les avancées nécessaires pour notre connaissance de l'œuvre qu'ont rendues 
possibles les analyses référentielles et contextuelles, mais il souligne aussi les erreurs d'attribution qu'elles peuvent engendrer, principalement celle de surestimer le caractère réaliste de l'écriture nervalienne.

3 La première partie de l'essai est ainsi dédiée à montrer les rapports qu'entretient effectivement l'œuvre nervalienne avec le réel, tout en invalidant une compréhension de celle-ci sous le signe du réalisme, même dans les aspects qui semblent s'y prêter le plus et qui font l'objet des premiers chapitres: l'influence du contexte politique et littéraire sur l'auteur (chap. 1), le genre autobiographique qui occupe une large part de son œuvre (chap. 2), l'écriture du voyage (chap. 4), l'intervention du pittoresque ou du fantastique (chap.5), et la description de paysages (chap.6). Le troisième chapitre revient pour sa part de façon synthétique sur les conflits d'interprétation dont Nerval fait l'objet pour conclure que sa «fantaisie [...] semble ancrer durablement Nerval dans le romantisme plus qu'elle ne le rapproche des réalistes» (p.53). La seconde partie propose une analyse des «structures de l'imaginaire» nervalien, tentant d'expliquer le sens des formes et figures que l'imagination donne aux dernières œuvres de l'auteur, au sein desquelles M. Collot lit un «triomphe sans partage de l'Imaginaire» (p. 164).

Le positionnement méthodologique adopté au sein de cet essai est très convaincant en ce qu'il a le mérite de croiser les points de vue et de tenter d'éclairer la singularité de l'écriture de Nerval dans ce qu'elle a de plus moderne. De même, nous ne pouvons qu'abonder dans le sens de $\mathrm{M}$. Collot quant à la question du réalisme supposé de Nerval. Les quelques regrets que nous pourrions formuler touchent plutôt au traitement de l'imaginaire, qui ne remplit pas jusqu'au bout toutes ses promesses.

5 Si M. Collot note bien l'ironie de Nerval lorsque ce dernier évoque ce qui a trait à la réalité, il semble parfois prendre trop au pied de la lettre ce que dit l'auteur de son imaginaire (la «distance ironique ne se maintient pas longtemps» p. 158). Il y décèle les aveux ou symptômes d'une domination de l'auteur par un imaginaire idéalisant, fantasmant, opérant des identifications en série, et ce jusqu'à l'aliénation ou la paranoïa. «Dans les dernières œuvres de Nerval, l'emprise de l'Imaginaire se fait de plus en plus forte. Le rempart des conventions sociales et littéraires ayant cédé [...] le poète ne peut s'empêcher de subir l'attrait de l'irréel» (p. 85). M. Collot insiste certes pour dire qu'il ne cherche pas à expliquer l'œuvre par la maladie, mais plutôt à montrer comment Nerval l'emploie pour en faire une ressource de sa création. Néanmoins l'œuvre nervalienne apparaît dans l'essai plutôt déterminée par la folie que s'en jouant, sur plusieurs niveaux d'écriture différents, pour la mettre au centre de ses questions.

6 En outre, l'hypothèse de lecture plaçant cette œuvre sous le signe de l'imaginaire plutôt que du réalisme, et faisant progresser l'auteur «du réel à l'imaginaire», ne convainc pas jusqu'au bout. Ce que Nerval semble développer dans ses dernières œuvres tient moins d'une opposition entre ces notions que d'une opposition entre ceux qui distinguent celles-ci et ceux qui les confondent. C'est précisément le partage dichotomique de l'existence entre ces deux pôles que met à l'épreuve le poète pour le récuser, et que reconduisent pourtant les analyses qui l'inféodent à l'un ou à l'autre de ces concepts (réalisme ou imaginaire). En ce sens, la notion d'Imaginaire empruntée à la psychanalyse ne nous semble pas toujours la plus opératoire pour rendre compte de ce que fait véritablement l'œuvre de Nerval, tant à la littérature qu'à notre pensée au sens large.

7 Ces quelques réserves sur le fond n'enlèvent rien néanmoins à la grande qualité de l'ouvrage, qui témoigne d'une grande connaissance de Nerval et d'une grande clarté 
d'exposition. Gérard de Nerval, du réel à l'imaginaire peut ainsi intéresser tant des spécialistes de l'auteur que des lectrices et lecteurs qui souhaiteraient s'y initier. 